\title{
Crowbar resistance value-switching scheme conjoint analysis based on statistical sampling for LVRT of DFIG
}

\author{
Yanbin $\mathrm{QU}^{\mathbf{1}}$, Le GAO ${ }^{1}$, Guangfu MA ${ }^{2}$, Huihui SONG ${ }^{1}$, \\ Shitao WANG $^{3}$
}

MPCE

\begin{abstract}
An active crowbar protective circuit is an effective and common approach for low voltage ride through (LVRT) of a doubly-fed induction generator (DFIG). The crowbar resistance value and its switching scheme both have crucial effects on safety recovery. The effects encountered are correlative dependence and interplay so that analyzing them from a single factor, as most existing LVRT control methods would do, obtains a partial optimal solution. This paper connects these two factors to analyze their coordination effects on the LVRT control, and to also investigate whether the global optimal performance of these factors can be achieved. The principles for
\end{abstract}

CrossCheck date: 13 June 2018

Received: 31 October 2017/Accepted: 13 June 2018/Published online: 8 September 2018

(C) The Author(s) 2018

$\triangle$ Huihui SONG

songhh@hitwh.edu.cn

Yanbin QU

quyanbin@hit.edu.cn

Le GAO

lelebrilliant@outlook.com

Guangfu MA

magf@hit.edu.cn

Shitao WANG

wangst_chn@hotmail.com

1 School of Information and Electrical Engineering, Harbin Institute of Technology at Weihai, No.2, West Wenhua Road, Weihai 264209, China

2 Department of Control Science and Engineering, Harbin Institute of Technology, No. 92, West Dazhi Street, Nangang District, Harbin 150001, China

3 State Grid of China Technology College, No. 500, Erhuan South Rd, Jinan, China resistance selection and the schemes for crowbar switching are discussed first. Next the coupling relationship is analyzed based on statistical sampling simulation data with different resistance values and various switching schemes. The results demonstrate that their coordination has critical influence on rotor peak current, DC-link voltage and reactive power. The optimal coordination will be different according to specific requirements. Hence the global optimal combination could be achieved when all requirements are taken into consideration.

Keywords Doubly-fed induction generator, Active crowbar, Switching scheme, Resistance value, Statistical sampling data

\section{Introduction}

The doubly-fed induction generator (DFIG) is prevalent with its excellent control performance and desirable pricequality ratio in the wind power market [1]. Nevertheless, its stator is highly sensitive to voltage fluctuations due to its direct connection to the grid, and its back-to-back partial scale converter can be easily damaged by rotor inrush current. Due to these features, DFIG is vulnerable to grid faults [2].

On the other hand, grid codes require wind turbines to be connected in low voltage faulty periods to support power systems and avoid fault deterioration, which is the so-called low voltage ride through (LVRT) [3]. This requirement is especially indispensable today because of the increasing capacity of wind energy in power systems.

Solutions of LVRT can be generally classified into two categories: software solutions, which are control strategies 
deliberately designed, and hardware solutions, which add protective devices into the DFIG system. Software solutions are in general economical, and hardware solutions are effective during severe voltage dips [4]. Active crowbar is one of the most commonly used hardware devices which is quite reliable and relatively cost effective [5].

The DFIG with active crowbar protection is illustrated in Fig. 1. When a severe grid fault is detected, the crowbar will be activated to damp the inrush current, and the rotor side converter (RSC) will be blocked to avoid damage.

If a grid fault is not severe, software methods are able to achieve LVRT by adopting specific control strategies for the converters. Figure 2 shows the logic diagram of a crowbar operation. In Fig. 2, (1): mild grid fault occurs; (2): severe grid fault occurs; (3): grid fault deteriorates; (4): turbines are permitted to disconnect; A: mild grid fault restored; B: faulty condition relieved; C: severe grid fault restored.

When the crowbar is activated, the RSC is blocked so that the DFIG is temporally out of control, and thereby operates as a squirrel cage induction generator (SCIG) that consumes reactive power. This could be detrimental to grid recovery. Therefore the crowbar should be switched off at a proper instant to restore the control of the DFIG and to reduce reactive power consumption [6]. Premature switching-off would not achieve sufficient damping for the inrush current, while postponed switching-off would prolong the uncontrolled time of the DFIG and consume additional reactive power.

Considering the significance of crowbar switching time, various switching schemes are proposed [5-11]. In [5], switching-off before fault recovery is recommended to reduce the crowbar operation time and quickly restore the control of the RSC, but the risk of DC-link over voltage still exists. The switching scheme proposed in [6] activates the crowbar both at the occurrence and recovery of the grid fault respectively, and each time the crowbar operation is limited by a minimum current threshold to reduce the total operation time. The switching schemes proposed in $[7,8]$

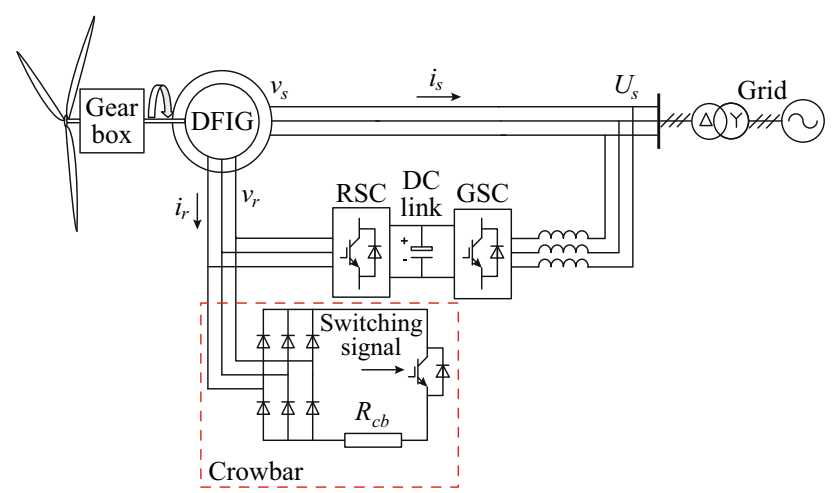

Fig. 1 DFIG with active crowbar protection

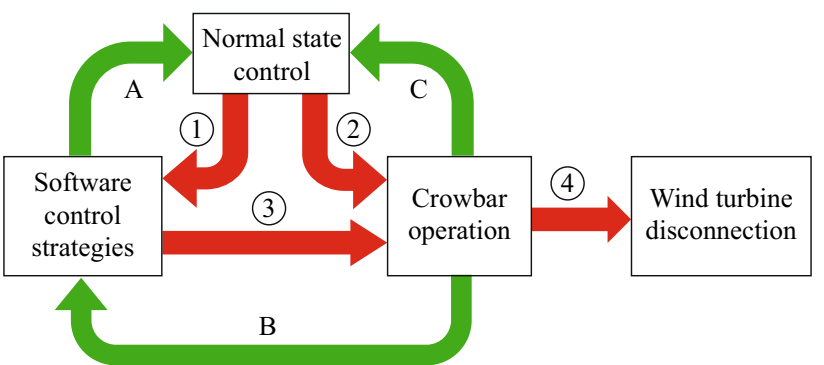

Fig. 2 Logic diagram of crowbar operation

enable multi-switching of the crowbar, and the activation and the deactivation of the crowbar are dependent on the rotor current [7] or the DC-link voltage [8]. The crowbar only operates for several times when the current or voltage exceeds the pre-set threshold to limit the total operation time. According to the codes of the power grid, if a grid fault is very severe, the time for the wind turbines maintaining their connection is relatively short. Hence some other schemes for short fault conditions, such as [9-11], suggest switching-off after the voltage recovery. Due to the relatively short crowbar activation time, these schemes can obtain preferable transient performance at the acceptable cost of reactive power consumption. Reference [9] reveals that the switching-off after the voltage recovery for 1 or 2 cycles could obtain ideal dynamic performance. And different switching schemes are compared in [10]. In order to further reduce reactive power consumption, the grid side converter (GSC), together with DC-link, can supply reactive power supply during the crowbar operation $[10,11]$.

Another crucial factor of the crowbar is the resistance value [9, 12-18]. Sufficient crowbar resistance can effectively damp the inrush current, whereas excessive increase of the resistance may incur current spikes and cause overvoltage on the DC-link when the crowbar switches. In [9], the relationship between crowbar resistance and rotor voltage is described, and the upper limit of the resistance is obtained. In [12], the short current is theoretically analyzed and the upper limit of the crowbar resistance is obtained according to the permitted DC-link voltage. Reference [13] reveals the effects of crowbar resistance under different voltage dips. In [14], the real-time adjustable crowbar resistance following the change of the system state is designed. Reference [15] introduces optimization indexes for crowbar resistance under different controllers during grid faults. And a nonlinear crowbar resistance calculation method based on frequency domain analysis is introduced in [16]. By comparing the effects of different resistance values, [17] suggests a crowbar resistance of 0.3 p.u., and the study of [18] selects 0.5 p.u..

Both the switching scheme and resistance value of the crowbar significantly influence LVRT performance. Their effects could represent correlative dependence and 
interplay, yet most existing researches analyze only from a single factor. Therefore the obtained solution of the switching scheme and resistance value might possibly not be coordinated. This paper connects these two factors to analyze their coordination effects for the LVRT control, and investigates whether the respective optimal performance of each factor can be achieved simultaneously. To achieve this purpose, the principles for resistance selection and the schemes for crowbar switching are discussed. And the coupling relationships are analyzed based on statistical sampling data with different resistance values and various switching schemes to illustrate their coordination effects.

The rest of this paper is organized as follows. In Section 2, the transient process of rotor current under severe grid fault is analyzed and the principles of crowbar selection and switching schemes are discussed. In Section 3, a statistical sampling method is introduced to analyze their coordination effects in respect to the rotor peak current, DC-link voltage and reactive power consumption. Simulations of different DFIG wind power systems with various switching schemes and resistance values are implemented on the MATLAB/Simulink platform and the results are discussed. And conclusions are given in Section 4.

\section{LVRT analysis of DFIG with crowbar}

DFIG can be described as a space vector model based on stator axis references in (1) and (2).

$$
\begin{aligned}
& \left\{\begin{array}{l}
v_{s}=R_{s} i_{s}+\mathrm{d} \psi_{s} / \mathrm{d} t \\
v_{r}=R_{r} i_{r}+\mathrm{d} \psi_{r} / \mathrm{d} t-\mathrm{j} \omega_{r} \psi_{r}
\end{array}\right. \\
& \left\{\begin{array}{l}
\psi_{s}=L_{s} i_{s}+L_{m} i_{r} \\
\psi_{r}=L_{m} i_{s}+L_{r} i_{r}
\end{array}\right.
\end{aligned}
$$

where $v, i, \psi$ represent space variables for voltage, current, and flux respectively; variables of rotor and stator are distinguished by subscripts $r$ and $s$ respectively; $R_{s}, R_{r}, L_{r}$, $L_{s}$ are the resistance and inductance of the rotors and stators, $L_{r}=L_{l r}+L_{m}, L_{s}=L_{l s}+L_{m}$, in which $L_{l r}$ and $L_{l s}$ are the leakage inductance of the rotors and stators, and $L_{m}$ represents the excitation inductance; $\omega_{r}$ is the angular frequency of the rotor voltage.

The relationship between the rotor current and voltage is described in the rotor axis reference with a differential equation:

$L_{r \sigma} \frac{\mathrm{d} i_{r}}{\mathrm{~d} t}=-R_{r} i_{r}-E_{r}+v_{r}$

where $L_{r \sigma}=L_{r}-L_{m}^{2} / L_{s}$ is the dynamic inductance of the rotor; $E_{r}$ is the induced electromotive force in the rotor wound.
Hypothesizing that a grid fault occurs when $t=t_{0}$, and the crowbar is activated immediately, then the stator voltage and rotor voltage can be described by (4) and (5).

$$
\begin{aligned}
& v_{s}= \begin{cases}U_{s} \mathrm{e}^{\mathrm{j} \omega_{s} t} & t<t_{0} \\
(1-p) U_{s} \mathrm{e}^{\mathrm{j} \omega_{s} t} & t \geq t_{0}\end{cases} \\
& v_{r}= \begin{cases}U_{r} \mathrm{e}^{\mathrm{j} s \omega_{s} t} & t<t_{0} \\
0 & t \geq t_{0}\end{cases}
\end{aligned}
$$

where $U_{s}$ and $U_{r}$ are the amplitude of the stator and rotor voltages; $\omega_{s}$ is the angular frequency of the stator voltage; $s=\left(\omega_{s}-\omega_{r}\right) / \omega_{s}$ represents slip; $p$ is used to describe the severity of the voltage $\operatorname{dip}, 0<p<1$. For instance, if the stator voltage drops to $20 \%$ of its nominal value, then $p=0.8$.

The stator flux linkage $\psi_{s}$ and induced electromotive force $E_{r}$ are given in (6) and (7):

$$
\begin{aligned}
& \psi_{s}= \begin{cases}U_{s} \mathrm{e}^{\mathrm{j} \omega_{s} t} /\left(j \omega_{s}\right) & t<t_{0} \\
(1-p) U_{s} \mathrm{e}^{\mathrm{j} \omega_{s} t} /\left(\mathrm{j} \omega_{s}\right) & \\
\quad+p U_{s} \mathrm{e}^{-\frac{t}{T_{s}}} /\left(\mathrm{j} \omega_{s}\right) & t \geq t_{0}\end{cases} \\
& E_{r}=\left\{\begin{array}{cc}
k_{s} s U_{s} \mathrm{e}^{\mathrm{j} s \omega_{s} t} & t<t_{0} \\
(1-p) k_{s} s U_{s} \mathrm{e}^{\mathrm{j} s \omega_{s} t} & \\
+(1-s) k_{s} p U_{s} \mathrm{e}^{\mathrm{j} \omega_{r} t} \mathrm{e}^{-\frac{t}{T_{s}}} & t \geq t_{0}
\end{array}\right.
\end{aligned}
$$

where $T_{s}=L_{s \sigma} / R_{s}$ is the time constant of the stator, $L_{s \sigma}=$ $L_{s}-L_{m}^{2} / L_{r}$ is the dynamic inductance of the stator; $k_{s}=$ $L_{m} / L_{s}$ is a constant for simplification. It can be observed that both the stator flux linkage $\psi_{s}$ and induced electromotive force $E_{r}$ in the faulty period involve two components, the steady component and transient component.

The rotor current is obtained by taking (5) and (7) into (3):

$$
\begin{aligned}
& i_{r}= \begin{cases}I_{0} \mathrm{e}^{\mathrm{j} s \omega_{s} t} & t<t_{0} \\
I_{1} \mathrm{e}^{-\mathrm{j} \omega_{r} t} \mathrm{e}^{-\frac{t}{T_{s}}} & \\
\quad+I_{2} \mathrm{e}^{\mathrm{j} s \omega_{s} t}+I_{3} \mathrm{e}^{-\frac{t}{T_{r}^{\prime}}} & t \geq t_{0}\end{cases} \\
& \left\{\begin{aligned}
I_{0}= & \frac{U_{r}-k_{s} s U_{s}}{R_{r}+\mathrm{j} s \omega_{s} L_{r \sigma}} \\
I_{1}= & \frac{k_{s}(1-s) p U_{s}}{R_{r}+R_{c b}-\mathrm{j} \omega_{r} L_{r \sigma}} \\
I_{2}= & -\frac{k_{s} s(1-p) U_{s}}{R_{r}+R_{c b}+\mathrm{j} s \omega_{s} L_{r \sigma}} \\
I_{3}= & \frac{U_{r}-k_{s} s U_{s}}{R_{r}+\mathrm{j} s \omega_{s} L_{r \sigma}}+\frac{k_{s} s(1-p) U_{s}}{R_{r}+R_{c b}+\mathrm{j} s \omega_{s} L_{r \sigma}} \\
& -\frac{k_{s}(1-s) p U_{s}}{R_{r}+R_{c b}-\mathrm{j} \omega_{r} L_{r \sigma}}
\end{aligned}\right.
\end{aligned}
$$

where $T_{r}^{\prime}=L_{r \sigma} /\left(R_{r}+R_{c b}\right)$ is the rotor time constant after crowbar activation; $R_{c b}$ is the crowbar resistance. 
Equation (8) indicates that the rotor inrush current consists of three components. $I_{1} \mathrm{e}^{-\mathrm{j} \omega_{r} t} \mathrm{e}^{-\frac{t}{T_{s}}}$ rotates at angular speed $\omega_{r}$ and damps with the stator time constant $T_{s}$. $I_{2} \mathrm{e}^{\mathrm{j} s \omega_{s} t}$ is a steady $\mathrm{AC}$ component rotating at angular speed $s \omega_{s}$. And $I_{3} \mathrm{e}^{-\frac{t}{T_{r}^{\prime}}}$ is a transient damping DC component damping with the rotor time constant $T_{r}^{\prime}$.

The damping speed of the inrush current is determined by time constants $T_{s}$ and $T_{r}^{\prime}$. And the rotor time constant $T_{r}^{\prime}$ is significantly reduced due to the operation of the crowbar, thus the main factor that influences the inrush current is $T_{s}$.

Although the switching schemes are different, they are basically designed according to the stator time constant $T_{s}$. And $T_{s}$ can be calculated once the parameters of DFIG are defined.

$T_{s}=\frac{L_{s \sigma}}{R_{S}}$

The limitation of the rotor current can be obtained considering the requirement of the inrush current (8) and (9). Under a severe fault, the voltage dip $p$ is close to 1 , and the component with $T_{r}^{\prime}$ damps much faster than the others, so that the items with $I_{2}$ and $I_{3}$ of $i_{r}$ can be omitted. Therefore, the amplitude of the inrush current is primarily determined by the item with $I_{1}$ that is:

$I_{r, \max }=\frac{p(1-s) k_{s} U_{s}}{\sqrt{R_{c b}^{2}+\left(\omega_{r} L_{r \sigma}\right)^{2}}}$

It can be observed that $I_{r, \text { max }}$ could be reduced with the increase of resistance $R_{c b}$, which theoretically explains the damping effects of the crowbar.

The resistance of the crowbar should be enough to damp the inrush current, whereas the DC-link voltage rises with the increase of the crowbar. Therefore, the resistance has maximum value.

$\sqrt{3} I_{r, \max } R_{c b} \leq U_{d c, l i m}$

where $U_{d c, \text { lim }}$ is the voltage limit for the DC-link.

Considering the limits of the rotor current (11) and DClink voltage (12), the limitation of crowbar resistance is:

$$
R_{c b, \max }=\frac{U_{d c, \text { lim }}(1-s) \omega_{s} L_{r \sigma}}{\sqrt{3\left[p(1-s) k_{s} U_{s}\right]^{2}-U_{d c, l i m}^{2}}}
$$

It can be observed from (13) that the upper limit resistance based on a certain DC-link voltage is related with the slip $s$ and the severity of the voltage dip $p$. The variation for the per unit DC-link voltage according to (13) is shown in Fig. 3.

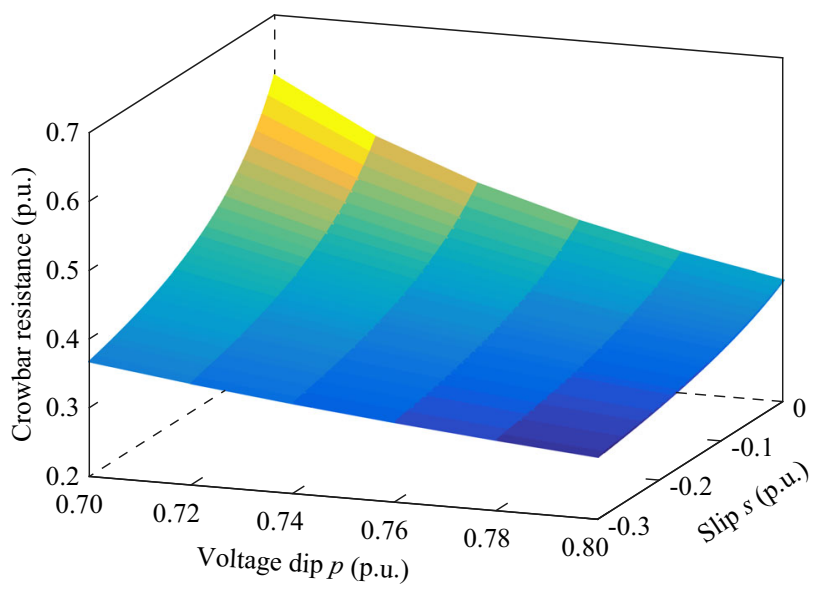

Fig. 3 Maximum crowbar resistance with slip $s$ and voltage dip $p$

\section{Conjoint analysis of resistance values and switching schemes}

Extensive research has been carried out either in the crowbar switching schemes or the resistance values, but most existing methods accomplish their analysis separately from a single angle of the crowbar resistance and switching schemes. Without considering their coupling relationship, the separate resolution for the two factors might not be coordinated. Therefore, to analyze the coordination effects of the resistance values and the switching schemes, a statistical sampling method for simulation data is proposed.

\subsection{Statistical sampling of simulation data}

The basic idea of the statistical sampling method is shown in Fig. 4. A coordinate system is established, where the $x$ axis is the switching-off time of various switching

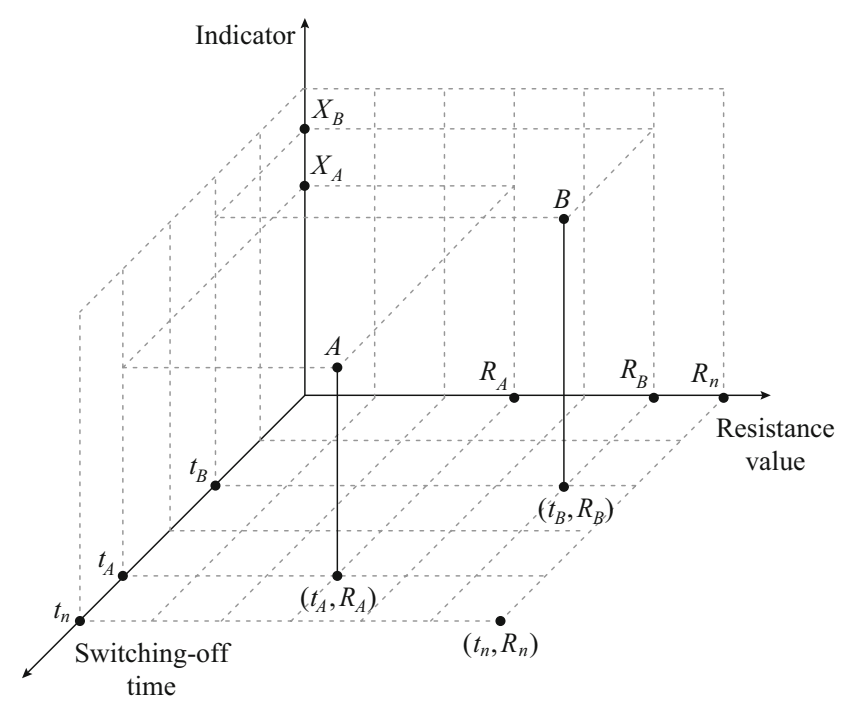

Fig. 4 Illustration for statistical sampling method 
schemes and the $y$ axis represents different crowbar resistance values. Thus each point on the $x O y$ surface is a combination of a specific switching scheme and a certain resistance value, marked as $\left(t_{n}, R_{n}\right)$ for short. The $z$ axis is an indicator sampled from simulation data generated under corresponding combinations of the two factors. The indicator is deliberately selected to evaluate the coordination effects of switching schemes and resistance values. Take Fig. 4 for illustration, points $A$ and $B$ are sampled data generated under the combinations $\left(t_{A}, R_{A}\right)$ and $\left(t_{B}, R_{B}\right)$ respectively, their vertical coordinates $X_{A}$ and $X_{B}$ are indicators to examine the corresponding LVRT performance. Similarly, by properly examining the indicators of any point $\left(t_{n}, R_{n}\right)$ on the $x O y$ surface, the coordination effects of crowbar switching schemes and resistance values can be analyzed.

The key to conjoint analysis of the two factors is the proper selection of the indicators. The main purposes of the indicators are: (1) correctly reflect the electromagnetic transients; (2) quantify the LVRT performance under any combination $\left(t_{n}, R_{n}\right)$.

The indicators are defined as follows: (1) the peak value of the rotor current; (2) the peak value of the DC-link voltage; (3) the peak value of the reactive power consumption.

These peak values are statistically sampled as indicators, which can directly quantify the LVRT performance and analyze the coordination effects. The indicators of the rotor current and DC-link voltage are used to examine the requirement for converter security, and that of the reactive power is used to reflect the influence on the power grid. The illustration for sampled data is shown in Fig. 5, where $I_{r, r i s e}$ is the rotor peak current occurred on voltage, $I_{r, o f f}$ is the rotor peak current occurred on crowbar, $U_{d c \text {, max }}$ is the peak voltage of DC-link, $Q_{c s m}$ is the peak value of reactive power consumption. The current is shown in its root mean square (RMS) value, and all of these variables are in per unit.

\subsection{Case study}

The case study is implemented to obtain the statistical sampling data and analyze the coordination effects of crowbar switching schemes and resistance values. The rated power we chose for these DFIGs are $1.5 \mathrm{MW}, 3 \mathrm{MW}$ and $5 \mathrm{MW}$ to validate the generality of the proposed method, and the parameters of these generators are listed in Appendix A Table A1. The control strategy of the DFIG converters is described in [19]. The simulated grid fault is a 3 -phase short circuit occurring on the stator terminals of the generator at $0.4 \mathrm{~s}$. The fault lasts for $200 \mathrm{~ms}$ and the severity of the voltage dip is 0.8 p.u.. The simulation model

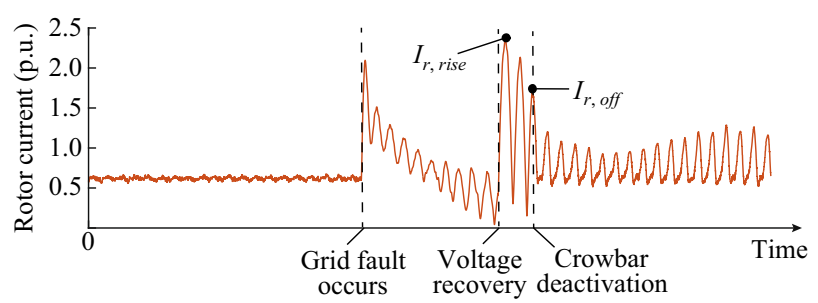

(a) Indicators for current

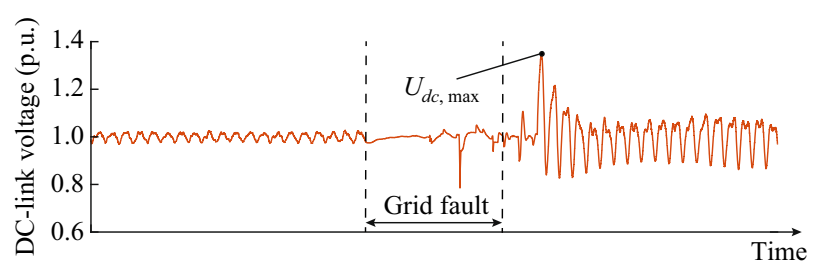

(b) Indicator for DC-link peak voltage

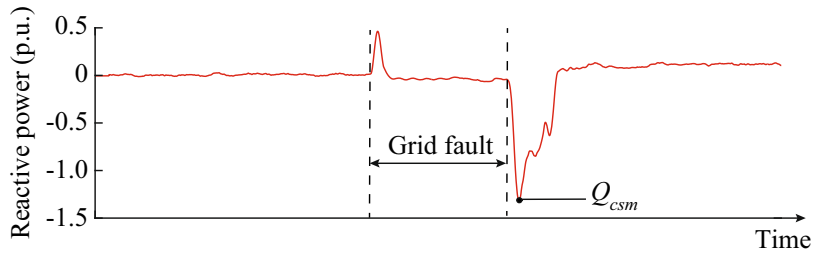

(c) Indicator for reactive power consumption

Fig. 5 Illustration for sampled data

is developed on the SimPowerSystem platform of the MATLAB/Simulink.

To generate different combinations of switching schemes and resistance values, the crowbar switching-off time is selected in the range of $1.6 \mathrm{~s}$ before voltage recovery to $1.6 \mathrm{~s}$ after recovery. And the scope of the crowbar resistance is selected according to the different ratings of the generators, $0.2-1.4$ p.u. for $1.5 \mathrm{MW}, 0.3-1.5$ p.u. for $3 \mathrm{MW}$ and $0.2-1.0$ p.u. for $5 \mathrm{MW}$.

\subsection{Statistical sampling results and conjoint analysis}

Figures 6-9 illustrate the statistical sampled indicators of three different ratings of the DFIGs. The two horizontal axes $T_{\text {off }}$ and $R_{c b}$ represent the switching-off time of different schemes and various resistance values respectively. The switching-off time $T_{\text {off }}$ is a relative value describing the time difference between the crowbar switching-off and voltage recovery.

\subsubsection{Peak current at voltage recovery}

Figure 6 illustrates the indicator $I_{r, r i s e}$. It indicates that both premature switching-off schemes and low resistance values contribute to the high values of $I_{r, \text { rise }}$, which has negative effects on the converters. 


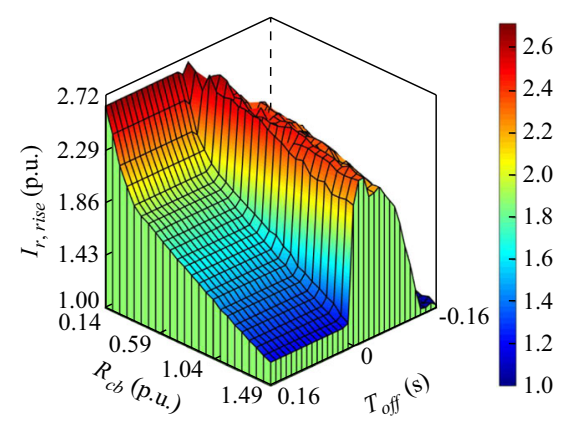

(a) $I_{r, \text { rise }}$ of $1.5 \mathrm{MW}$ DFIG

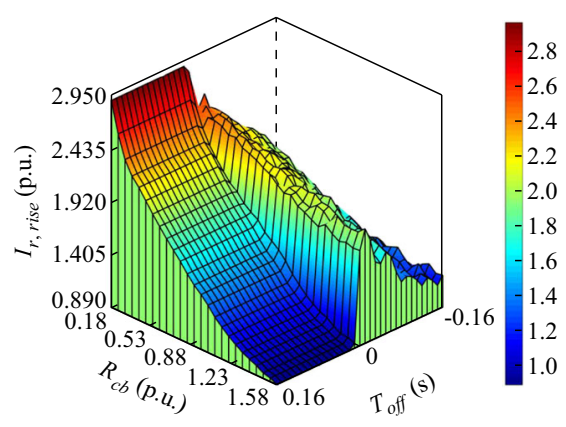

(b) $I_{r \text {, rise }}$ of $3 \mathrm{MW}$ DFIG

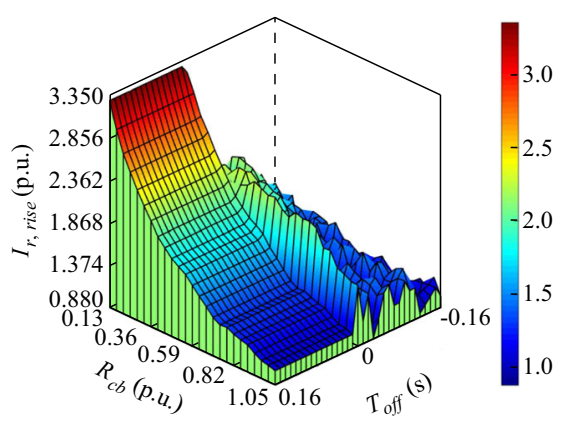

(c) $I_{r, \text { rise }}$ of 5 MW DFIG

Fig. 6 Peak current at voltage recovery

From the perspective of the switching scheme, it can be observed that the crowbar switching-off before voltage recovery $\left(T_{\text {off }}<0\right)$ generates a much higher value of the peak current than switching-off after voltage recovery $\left(T_{\text {off }}>0\right)$. This peak current at recovery cannot be damped effectively if the crowbar is switched off before recovery. Hence premature switching-off may lead to potential threats on the safety of the converters.

On the other hand, the influence of resistance can also be observed from Fig. 6. When the crowbar is deactivated after voltage recovery, the peak current is reduced with the increase of crowbar resistance which is in good agreement with discussions in former sections. Therefore, postponed switching schemes and increased resistance can effectively reduce the peak current at the moment of voltage recovery.

By comparing the data in Fig. 6a-6c for different ratings of generators, it is observed that the $I_{r, \text { rise }}$ of early switching-off is decreased with the growing rated power of the DFIG, and the effects of postponed switching schemes with increased resistance have similar change trends among different ratings.

\subsubsection{Peak current at crowbar switching-off}

Figure 7 shows the coordination effects on $I_{r, o f f}$, which directly determines the ultimate result of the LVRT. A high value of this peak current indicates crowbar protection failure.

Taking the switching scheme into consideration, $I_{r, \text { off }}$ is much higher at the instant of voltage recovery than at other times, which is possibly generated by the overlapped transient process of crowbar switching-off and grid fault recovery. Before or after the recovery, the peak current is significantly reduced. Hence, it is suggested to avoid switching-off around voltage recovery. In practice, the instant of fault clearance is unpredictable, thus we cannot ensure crowbar deactivating before voltage recovery. Therefore, postponing switching-off is more practical. The obvious periodic fluctuation of this peak current might be related to the frequency of the transient inrush current. And among the different rated powers of the DFIGs, the influence of crowbar switching-off time on $I_{r, \text { off }}$ is similar

As for the effects of crowbar resistance, it can be seen that insufficient resistance values generate violent fluctuations of the peak current $I_{r, o f f}$, signifying that this resistance

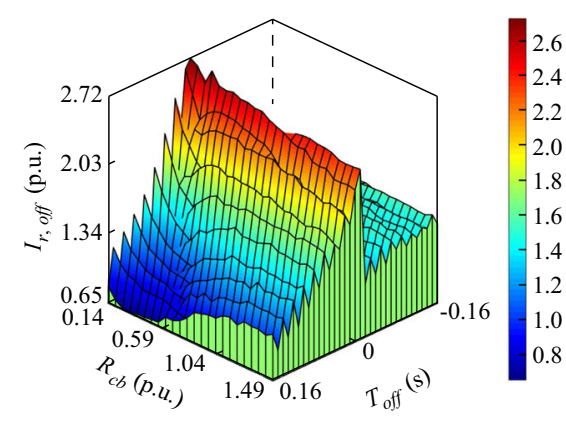

(a) $I_{r, \text { off }}$ of 1.5 MW DFIG

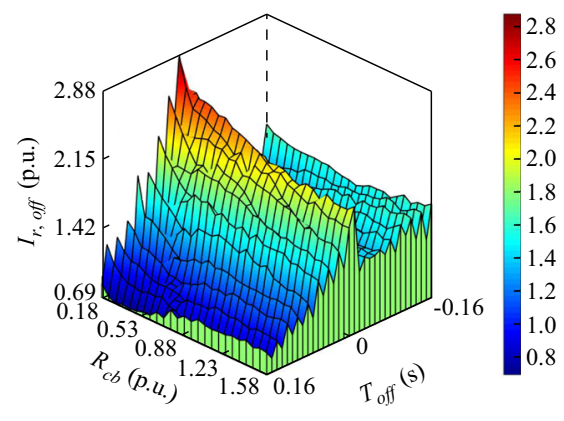

(b) $I_{r \text {, off }}$ of $3 \mathrm{MW}$ DFIG

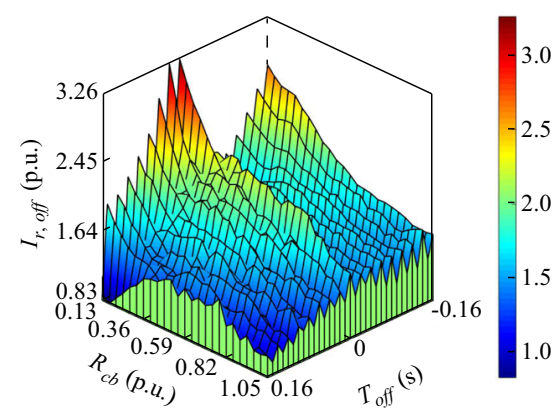

(c) $I_{r, \text { off }}$ of $5 \mathrm{MW}$ DFIG

Fig. 7 Peak current at crowbar switching-off 
is inadequate for damping the inrush current. And with resistance increasing, the fluctuations are reduced. Whereas it is particularly notable that $I_{r, o f f}$ ascends again when $R_{c b}$ is extra large. Therefore the adequate resistance needs to damp the inrush current effectively and to avoid $I_{r, \text { off }}$ increasing again. It can be seen from Fig. 7 that the minimum of $I_{r, o f f}$ appears when $R_{c b}$ is roughly 0.4 p.u. for 1.5 MW, 0.4-0.5 p.u. for $3 \mathrm{MW}$. And for the $5 \mathrm{MW}$ DFIG, $I_{r, o f f}$ reduces fastest, while the minimum value is not obvious.

\subsubsection{DC-link peak voltage}

The DC-link peak voltage $U_{d c \text {, max }}$ is illustrated in Fig. 8. $U_{d c \text {, max }}$ is extra large when $T_{\text {off }}<0$. Considering the relatively small capacity of the converters, this high voltage could definitely incur damage. Thus, the crowbar is supposed to be deactivated after voltage recovery from the perspective of $U_{d c, \text { max }}$.

Another notable phenomenon is that the increase of resistance curbed the fluctuation of $U_{d c \text {,max }}$ among different switching schemes. Distinct from peak current and reactive power, there are more irregular fluctuations of the DC link peak voltage when $R_{c b}$ is small. And these fluctuations decrease to some extent with the increasing resistance. Nevertheless, the extra large values of $R_{c b}$ also lead to peak voltage rising. Hence $R_{c b}$ has both an upper bound and lower bound, and should be considered together with other indicators.

As is shown in Fig. 8, the optimal resistance values are respectively 0.5 p.u. for $1.5 \mathrm{MW}, 0.6$ p.u. for $3 \mathrm{MW}$, and 0.4 p.u. for $5 \mathrm{MW}$. Although the various rated powers of the DFIGs have different optimal values, the changing trends among these ratings of generators are similar. Comparing the optimal solutions according to the indicators for peak current and DC-link voltage in Fig. 7 and Fig. 8, the optimal combinations of switching schemes and resistance values of $I_{r, \text { off }}$ and $U_{d c, \text { max }}$ are compatible for the ratings of $1.5 \mathrm{MW}$ and $3 \mathrm{MW}$, while they are mismatched for the $5 \mathrm{MW}$ system.

\subsubsection{Maximum reactive power consumption}

The maximum reactive power consumption $Q_{c s m}$ is shown in Fig. 9. When the crowbar is activated, DFIG operates as a SCIG that consumes reactive power. In order to investigate the authentic influence on reactive

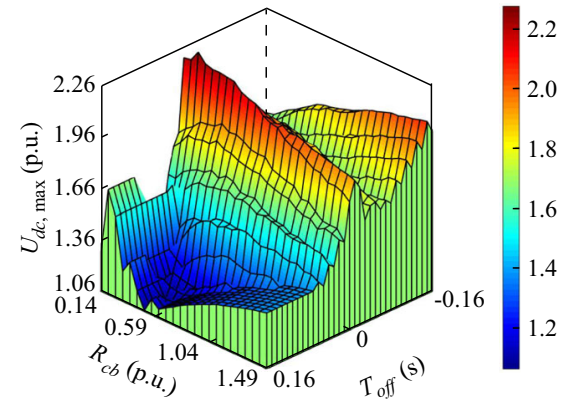

(a) $U_{d c, \max }$ of $1.5 \mathrm{MW}$ DFIG

Fig. 8 Peak DC-link peak voltage

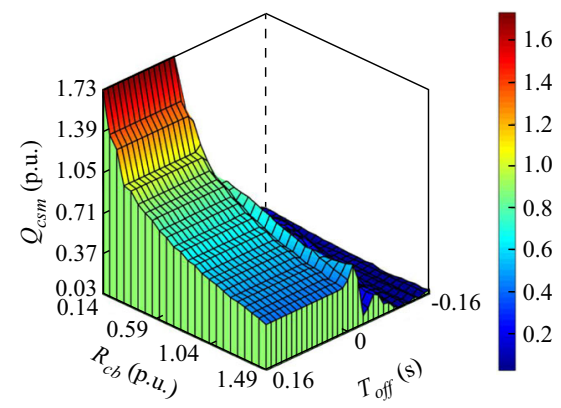

(a) $Q_{c s m}$ of $1.5 \mathrm{MW}$ DFIG

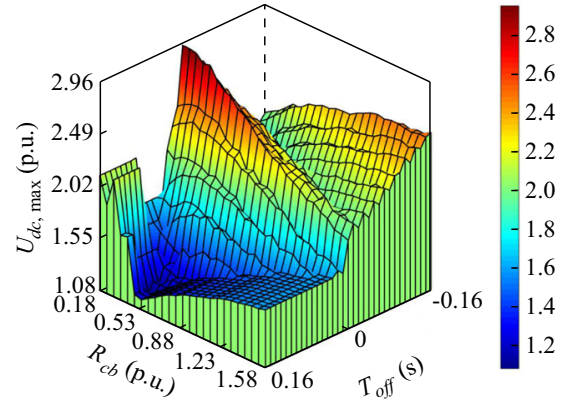

(b) $U_{d c \text {, max }}$ of 3 MW DFIG

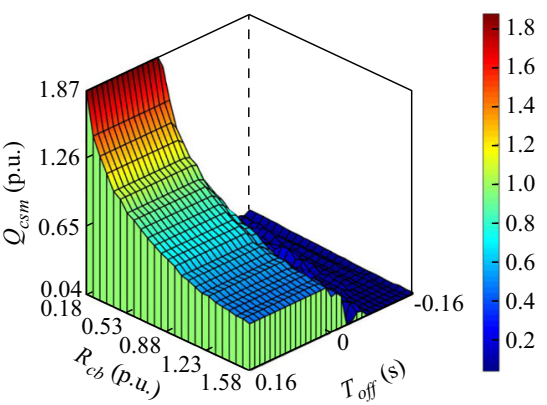

(b) $Q_{c s m}$ of 3 MW DFIG

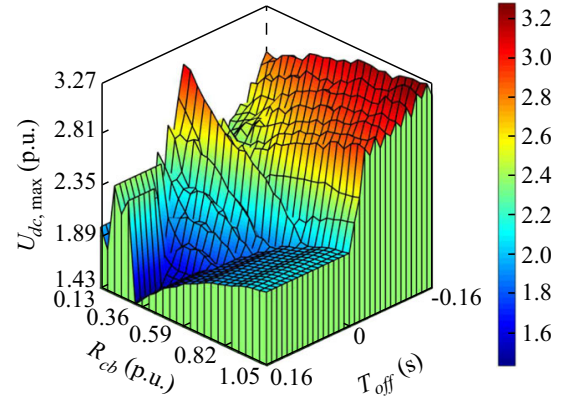

(c) $U_{d c, \text { max }}$ of 5 MW DFIG

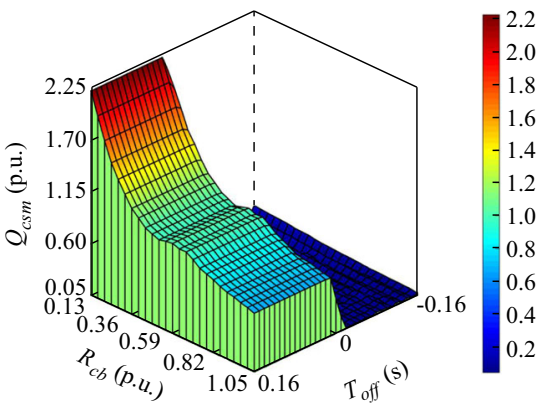

(c) $Q_{c s m}$ of $5 \mathrm{MW}$ DFIG

Fig. 9 Reactive power consumption 
consumption, no reactive compensation method is utilized during simulations. Thus the value of $Q_{c s m}$ is related directly to the effect of the switching scheme and crowbar resistance.

According to Fig. 9, early switching-off schemes produce less reactive consumption. And without reactive compensation, switching-off after recovery enlarges the reactive consumption. $Q_{c s m}$ becomes larger when the resistance value is low, and vice versa. This indicator supports the combination of early switching-off schemes and high resistance values of the crowbar. And the regularity is similar in the aspect of different ratings.

\subsection{Discussion}

The coordination effects are analyzed by statistically sampled indicators. The coupling effects on specific indicators are diverse. While for each individual indicator, the fluctuation trends among different ratings of the DFIGs are similar. Thus the global optimal coordination needs comprehensive consideration of all indicators. The indicators of peak current $\left(I_{r, \text { rise }}\right.$ and $\left.I_{r, \text { off }}\right)$ show that the combination of premature switching-off schemes and small crowbar resistance values are not practical due to the high inrush current. The indicator of the DC-link voltage $\left(U_{d c, \max }\right)$ puts both upper and lower limits on resistance values, and indicates that dangerous high voltage can be caused by premature switching off schemes, and the indicator for reactive consumption $\left(Q_{c s m}\right)$ supports the combination of the switch off crowbar before recovery and high resistance values. The differences of optimal combinations for each indicator are listed in Table 1.

The global optimal coordinate combinations can be obtained with all these indicators taken into consideration. Based on the different priorities of these indicators, the global optimal combinations are not unique. For example, if the safety of the DC-link is the priority, the performances of premature switching-off and higher resistance values are contradictive with the requirements. Thus a trade-off should be considered. Due to the priority of the DC-link voltage, postponed switching-off and resistance under the
DC-link limitation are adopted in coordination. And the requirements for reactive power could be satisfied by other reactive compensations. Thereby the indicators of reactive power could compromise with the other indicators for global optimal coordination.

To demonstrate the performance of the global optimal combination of switching-off schemes and crowbar

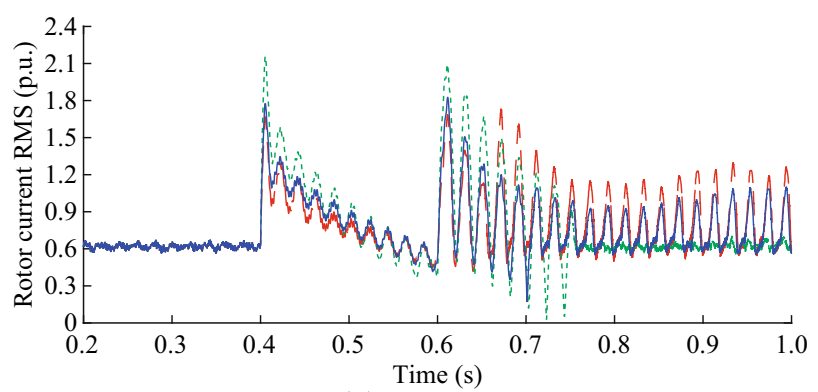

(a) Rotor current

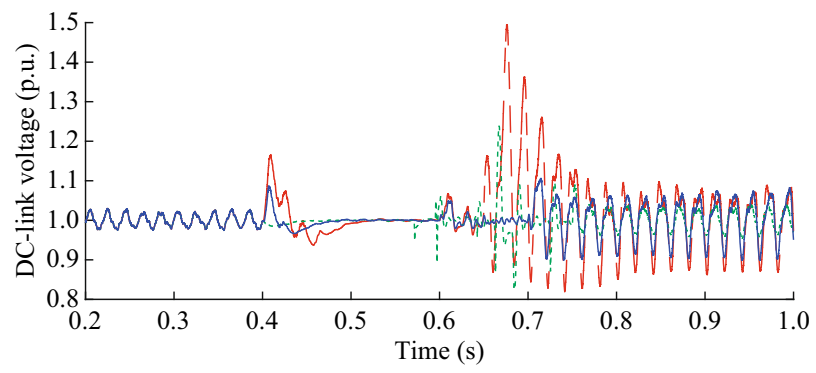

(b) DC-link peak voltage

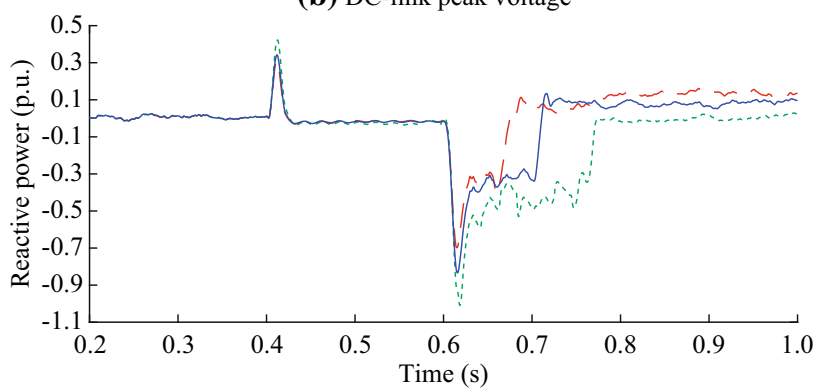

(c) Reactive power

- Combination 1 ; - - Combination 2; - Combination optimum

Fig. 10 LVRT performance of different combinations

Table 1 Difference of optimal combinations for each indicator

\begin{tabular}{lll}
\hline Indicator & Switching scheme & Resistance limit \\
\hline$I_{r, \text { rise }}$ & Switching-off after recovery & No upper limit \\
$I_{r, \text { off }}$ & Avoid switching-off at recovery & Optimal range (1.5 MW: 0.4 p.u.; 3 MW: 0.4-0.5 p.u.; 5 MW: not obvious) \\
$U_{d c, \text { max }}$ & Switching-off after recovery & Optimal range (1.5 MW: 0.5 p.u.; 3 MW: 0.6 p.u.; 5 MW: 0.4 p.u.) \\
$Q_{c s m}$ & Switching-off before recovery & No upper limit \\
\hline
\end{tabular}


resistance, the comparisons among the proposed global optimal combinations and other common combinations are implemented based on the 1.5 MW DFIG under a $80 \%$ voltage dip during 0.4 to $0.6 \mathrm{~s}$, and the related switchingoff schemes and resistance selection methods can be found in $[8,9,11,17]$ : (1) combination $1, T_{\text {off }}=0.5 \mathrm{~s}, R_{c b}=0.72$ p.u.; (2) combination $2, T_{o f f}=1.5 \mathrm{~s}, R_{c b}=0.30$ p.u.; (3) combination optimum, $T_{o f f}=0.1 \mathrm{~s}, R_{c b}=0.50$ p.u.. Figure 10 illustrates the LVRT performance of these combinations.

In Fig. 10a, it can be seen that combination 1 curbs the rotor inrush current most effectively on the grid fault occurrence and recovery, while combination 2 leads to the highest inrush current. On the other hand, combination 2 induces the minimum fluctuation after the crowbar switching-off while combination 1 leads to the maximum fluctuation. And the performance of the combination optimum is between them.

The comparison of the DC-link voltage is shown in Fig. 10b. It is notable that combination 1 generates the most violent DC-link voltage fluctuation, and the maximum voltage exceeds the safety limit. Hence combination 1 may be impractical from the perspective of DC-link voltage safety. And combination 2 leads to a quite steady voltage during the grid fault and after the crowbar switching-off, while the voltage fluctuates during the crowbar operation after the voltage recovery. The combination optimum obtains the best performance from the voltage recovery to crowbar switching-off, and the fluctuation of voltage after switching-off is also acceptable.

The reactive power consumption is shown in Fig. 10c. Combination 1 consumes minimum reactive power, and combination 2 consumes the maximum. The reactive power consumption of the combination optimum is between them.

Based on the above comparisons, combination 1 consumes minimum reactive power and damps the current most effectively, but generates the highest current fluctuation after switching-off and fails to reduce the DC-link over voltage. Combination 2 shows better performance in DC-link voltage but consumes the maximum reactive power and the inrush current damping is insufficient. Although the combination optimum does not obtain the best performance in any single aspect, it obtains acceptable performance in all of these aspects due to its better coordination of switching schemes and resistance values, therefore its performances are the global optimal.

\section{Conclusion}

This paper investigates the coordination effects of different crowbar switching schemes and resistance values. The principles for resistance selection and the schemes for crowbar switching are discussed. A statistical sampling method for simulation data with different resistance values and various switching schemes is introduced. The results demonstrate that their coordination effects have critical influence on rotor peak current, DC-link voltage and reactive power. And the optimal coordination will be different according to specific requirements. Hence a compromise has to be made based on their priorities. The global optimal combination could be finally obtained with all requirements taken into consideration.

Acknowledgements This work was supported by the Natural National Science Foundation of China (No. 61773137, No. 61403099), and the Natural National Science Foundation of Shandong Province (No. 2014BSA10007, No. 2014J14LN92).

Open Access This article is distributed under the terms of the Creative Commons Attribution 4.0 International License (http:// creativecommons.org/licenses/by/4.0/), which permits unrestricted use, distribution, and reproduction in any medium, provided you give appropriate credit to the original author(s) and the source, provide a link to the Creative Commons license, and indicate if changes were made.

\section{Appendix A}

Parameters of DFIGs are shown in Table A1.

Table A1 Parameters of DFIGs

\begin{tabular}{lllllllr}
\hline No. & $P_{\text {nom }}(\mathrm{MW})$ & $V_{\text {nom }}(\mathrm{V})$ & $R_{s}$ (p.u.) & $R_{r}$ (p.u.) & $L_{l s}$ (p.u.) & $L_{l r}$ (p.u.) & $L_{m}$ (p.u.) \\
\hline 1 & 1.5 & 690 & 0.0084 & 0.0083 & 0.167 & 0.1323 & 5.419 \\
2 & 3.0 & 690 & 0.0070 & 0.0050 & 0.070 & 0.1700 & 3.300 \\
3 & 5.0 & 690 & 0.0030 & 0.0040 & 0.125 & 0.0100 & 2.500 \\
\hline
\end{tabular}




\section{References}

[1] Jadhav HT, Ranjit R (2013) A comprehensive review on the grid integration of doubly fed induction generator. Int J Electr Power Energy Syst 49:8-18

[2] Cardenas R, Pena R, Alepuz S et al (2013) Overview of control systems for the operation of DFIGs in wind energy applications. IEEE Trans Ind Electron 60(7):2776-2798

[3] Mansour M, Islam SM (2012) Review of international grid codes for wind power integration: diversity, technology and a case for global standard integration. Renew Sustain Energ Rev 16(6):3876-3890

[4] Sajjad T, Mohammadiivatloo B (2016) A comprehensive review of low voltage ride through of doubly fed induction wind generators. Renew Sustain Energ Rev 57:412-419

[5] Lopez J, Gubia E, Olea E (2009) Ride through of wind turbines with doubly FED induction generator under symmetrical voltage Dips. IEEE Trans Ind Electron 56(10):4246-4254

[6] Pannell G, Atkinson DJ, Bashar Z (2010) Minimum-threshold crowbar for a fault-ride-through grid-code-compliant DFIG wind turbine. IEEE Trans Energy Convers 25(3):750-759

[7] Peng L, Francois B, Li YD (2009) Improved crowbar control strategy of DFIG based wind turbines for grid fault ride-through. In: Proceedings of 24th annual IEEE applied power electronics conference and exposition, Washington, USA, 15-19 February 2009, pp 1932-1938

[8] Zhang L, Jin XM, Zhan LY (2011) A novel LVRT control strategy of DFIG based rotor active crowbar. In: Proceedings of Asia-Pacific power and energy engineering conference, Wuhan, China, 25-28 March 2011

[9] Xu DG, Wang W, Chen N (2010) Dynamic characteristic analysis of doubly-fed induction generator low voltage ridethrough based on crowbar protection. Proc CSEE 30(22):29-36

[10] $\mathrm{Hu} \mathrm{JB}, \mathrm{He}$ YK (2008) Low voltage ride through operation and control of doubly fed induction generator wind turbines. Autom Electr Power Syst 32(2):49-52

[11] Meegahapola L, Littler T, Flynn D (2010) Decoupled-DFIG fault ride-through strategy for enhanced stability performance during grid faults. IEEE Trans Sustain Energy 1(3):152-162

[12] Morren J, de Haan SW (2007) Short-circuit current of wind turbines with doubly fed induction generator. IEEE Trans Energy Convers 22(1):174-180

[13] Zhou HL, Yang G (2009) Short circuit current characteristics of doubly fed induction generator with crowbar protection under different voltage dips. Proc CSEE 29(S1):184-191

[14] Ren Y, Zhang W (2011) A novel control strategy of an active crowbar for DFIG-based wind turbine during grid faults. In: Proceedings of international electric machines and drives conference, Niagara Falls, Canada, 15-18 May 2011, pp 1137-1142

[15] Anaya-Lara O, Liu ZF, Quinonez-Varela G et al (2008) Optimal DFIG crowbar resistor design under different controllers during grid faults. In: Proceedings of 2008 third international conference on electric utility deregulation and restructuring and power technologies, Nanjing, China, 6-9 April 2008, pp 2580-2585

[16] Luo H, Lin MY, Cao Y et al (2016) A calculation method for the nonlinear crowbar circuit of DFIG wind generation based on frequency domain analysis. J Power Electron 16(5):1884-1893

[17] Kasem AH, El-Saadany EF, El-Tamaly HH (2008) An improved fault ride-through strategy for doubly fed induction generatorbased wind turbines. IET Renew Power Gener 2(4):201-214

[18] Hansen AD, Michalke G (2007) Fault ride-through capability of DFIG wind turbines. Renew Energ 32(9):1594-1610

[19] Song HH, Zhang Q, Qu YB et al (2016) An energy-based LVRT control strategy for doubly-fed wind generator. In: Proceedings of 11th UKACC international conference on control, Belfast, UK, 31 August-2 September 2016

Yanbin QU received the Ph.D. degree from Harbin Institute of Technology, China, in 2003. He is currently a professor of the Department of Electrical Engineering and Automation, Harbin Institute of Technology. His background areas are control theory application, power electronics and electric drives; and his main current research areas are control technology in renewable energy and microgrid.

Le GAO received the B.E. degree from Shanxi Agricultural University, China, in 2016. He is currently working towards the M.E. degree in Harbin Institute of Technology at Weihai since 2016. His main research interests include wind power control and fault ride through technology.

Guangfu MA received his M.S. and Ph.D. degrees in electrical engineering from Harbin Institute of Technology in 1987 and 1993, respectively. He is currently a professor in the Department of Control Science and Engineering, Harbin Institute of Technology, where he currently teaches and performs research in the fields of nonlinear control, satellite attitude control and formation flying.

Huihui SONG received the Ph.D. degree from Harbin Institute of Technology, China, in 2012. She is an associate professor in Harbin Institute of Technology at Weihai currently. Her current research interests include nonlinear control technology in renewable energy and microgrid.

Shitao WANG received the Ph.D. degree in power electronics from Zhejiang University. He is now working as a vice professor for State Grid of China Technology Colleges. He is also a 1st-class national enterprise training lecturer in electrical enterprise consulting. His main interests include power electronic applications in power grids, smart distribution networks, and new energy technologies. 